\title{
Risk Factors of Saphenous Vein Insufficiency in Female Patients in Riyadh, Saudi Arabia
}

\author{
Abdullah Alwahbi ${ }^{1}$, Amal Alamri ${ }^{2}$, Wafa Alotaibi ${ }^{3}$ \\ 1. Vascular Surgery, King Abdulaziz Medical City, Ministry of National Guard Health Affairs, Riyadh, SAU 2. Vascular \\ Surgery, King Saud Bin Abdulaziz University for Health Sciences, Riyadh, SAU 3. Vascular Surgery, King Saud Bin \\ Abdulaziz University for Health Sciences, Riyadh, SAU
}

Corresponding author: Abdullah Alwahbi, wahbia@ngha.med.sa

\begin{abstract}
Background: Venous reflux most frequently occurs in the great saphenous vein (GSV), which is the most commonly diseased vein and is associated with venous insufficiency and varicose veins.
\end{abstract}

Objective: We aimed, in this study, to determine risk factors for saphenous vein insufficiency in female patients in Riyadh, Saudi Arabia.

Methods: This was a retrospective cohort study. Data were collected from the medical records of adult female patients who developed saphenous vein insufficiency at King Abdulaziz Medical City, between 2015 and 2017.

Results: A total of 97 subjects participated in the study, 53 patients had saphenous vein reflux while 44 patients did not have reflux. Leg swelling was the only symptom that showed a significant difference between the two groups ( $\mathrm{p}<0.001)$; patients with reflux had significantly higher rates of endovenous laser therapy $(\mathrm{p}=0.021)$. While the same patient group showed significantly lower rates of sclerotherapy compared to patients without reflux $(\mathrm{p}=0.006)$. The proportion of hypertension patients without reflux $(22.7 \%)$ was significantly larger than that of hypertension patients with reflux $(1.9 \%)(p=0.001)$.

Conclusion: More research is encouraged to provide better understanding and management of saphenous vein insufficiency in the Saudi population, especially in females who are at high risk.

Categories: Cardiac/Thoracic/Vascular Surgery, General Surgery

Keywords: saphenous vein, venous insufficiency, retrospective, female population, saudi arabia

\section{Introduction}

Received 01/02/2020 Review began 01/03/2020 Review ended 01/09/2020 Published 01/13/2020

๑) Copyright 2020 Alwahbi et al. This is an open access article distributed under the terms of the Creative Commons Attribution License CC-BY 3.0., which permits unrestricted use, distribution, and reproduction in any medium, provided the original author and source are credited.
Lower limb saphenous vein insufficiency is a frequent medical disorder which is detected in about $30 \%$ of adult females and about $15 \%$ of males in the European community [1]. Most of the patients with saphenous vein insufficiency have an involvement of the great saphenous vein (GSV) followed by the small saphenous vein [2-3].

Traditional clinical manifestations symptoms and signs of saphenous vein insufficiency are edema, discomfort, aching, in addition to muscle cramps [4]. Some complications may occur with saphenous vein insufficiency comprising venous ulcerations, eczema, and superficial thrombophlebitis [5-7].

Chronic venous insufficiency (CVI) can have a large influence on the quality of life of patients that can be compared to other frequent disorders [8]. It is also linked to increased healthcare costs. The treatment of saphenous vein insufficiency decreases the symptoms as well as complications. Moreover, it improves health-related quality of life [9].

Turning to management modalities, during the past few years, endogenous laser ablation therapy of saphenous veins has shown to be safe. Additionally, long-term follow up showed comparable results that were sometimes superior to conventional surgical strategies [10-11]. However, the success of this relatively novel technique is limited by some post-procedure complications like post-procedure pain, phlebitis, and tenderness, for instance [12-14]. Yet, data on risk factors of saphenous vein insufficiency is scarce and confusing in medical literature, especially in the gulf area and Arab region [15].

Since data regarding saphenous vein insufficiency are lacking, this retrospective cohort study aimed to determine risk factors associated with saphenous vein insufficiency in female patients in Riyadh, Saudi Arabia.

\section{Materials And Methods}


This was a retrospective cohort study conducted to determine risk factors associated with saphenous vein insufficiency in female patients in Riyadh, Saudi Arabia. Data were collected from the medical records of the female patients who developed saphenous vein insufficiency at the King Abdulaziz Medical City hospital between 2015 and 2017. Data were collected from charts, Best-care systems were then recorded in data collection forms and finally entered into excel spreadsheets.

In addition to the patients' characteristics (age, weight, height, body mass index (BMI)), previous pregnancies, symptoms of saphenous vein insufficiency, previous treatment of varicose veins, and risk factors of saphenous vein insufficiency were collected. Symptoms collected included leg pain, leg swelling, leg lymphedema, and skin pigmentation. Previous treatment of saphenous vein insufficiency included previous vein surgery, previous endovenous laser therapy, and previous sclerotherapy. Risk factors included diabetes mellitus, hypertension, high lipid levels, smoking, heart disease, field work, oral contraceptive pills, and family history of varicosities.

Participation in the study was voluntary, and every respondent provided written informed consent. Participants were not asked to provide their names, and confidentiality and anonymity were maintained throughout the study. Only the research team had access to the data

\section{Statistical analyses}

Data were represented in terms of frequencies (number of patients/ cases) and valid percentages for categorical variables. Mean, standard deviations (SD), minimum and maximum values were used to describe the numerical variable. Chi-square test was used to compare categorical variables between the subgroups (cross-tabulation) while one-way Anova test was used to compare numerical variables between the subgroups. All P values < 0.05 were considered statistically significant. IBM Statistical Package for the Social Science (SPSS; IBM Corp, Armonk, NY) version 21 for Microsoft Windows was used to perform all statistical calculations.

\section{Results}

The following patients' characteristics were collected:

\section{Age}

The mean \pm SD age of participating females was $43 \pm 12.7$ years with a minimum value of 21 and a maximum value of 74 years.

\section{Physical examination}

The mean weight was $77.7 \pm 13.9 \mathrm{~kg}$ with a minimum value of $53 \mathrm{~kg}$ and a maximum value of $136 \mathrm{~kg}$, the mean height was $159.5 \pm 5.2 \mathrm{~cm}$ with a minimum value of $143 \mathrm{~cm}$ and a maximum value of $173 \mathrm{~cm}$, and the mean body mass index (BMI) was $30.7 \pm 6 \mathrm{~kg} / \mathrm{m} 2$ with a minimum value of $19.9 \mathrm{~kg} / \mathrm{m} 2$ and a maximum value of $55.9 \mathrm{~kg} / \mathrm{m} 2$.

\section{Previous pregnancies}

Regarding the number of previous pregnancies, we found that $22.7 \%$ of patients $(n=20)$ had a total of three pregnancies, $17 \%$ had a total of four pregnancies, $17 \%$ had a total of two pregnancies, and $15.9 \%$ had a total of five pregnancies.

\section{Symptoms of venous insufficiency}

We found that the vast majority ( $\mathrm{n}=96,99 \%)$ had venous insufficiency symptoms; 96 (99\%) patients suffered from leg pain, 77 (79.4\%) patients experienced leg swelling, only four (4.1\%) had leg lymphedema, and only one (1\%) experienced skin pigmentation. Additionally, symptoms were compared with patients who had saphenous reflux and those who did not have saphenous reflux using the chi-square test; $P$ value $\leqslant 0.05$ was considered significant. There was a significantly higher $(\mathrm{P}<0.001)$ rate of leg swelling in patients with reflux (100\%) compared to patients without reflux (54.45\%). However, leg pain, leg lymphedema, and skin pigmentation did not differ in the two groups (Table 1). 


\section{Cureus}

\begin{tabular}{|c|c|c|c|c|}
\hline Symptom & Yes/ No & With Reflux (N=53) & Without Reflux (N=44) & P Value \\
\hline \multirow{2}{*}{ Leg pain } & Yes & $53(100)$ & $43(97.7)$ & \multirow{2}{*}{0.270} \\
\hline & No & 0 & $1(2.27)$ & \\
\hline \multirow{2}{*}{ Leg swelling } & Yes & $53(100)$ & 24 (54.45) & \multirow{2}{*}{$<0.001^{*}$} \\
\hline & No & 0 & $20(45.45)$ & \\
\hline \multirow{2}{*}{ Leg lymphedema } & Yes & $4(7.54)$ & 0 & \multirow{2}{*}{0.063} \\
\hline & No & 49 (92.45) & $44(100)$ & \\
\hline Skin pigmentation & Yes & $1(1.88)$ & 0 & 0.360 \\
\hline \multicolumn{5}{|c|}{ TABLE 1: Symptoms of venous insufficiency reported in the study population } \\
\hline
\end{tabular}

\section{Previous treatment of venous insufficiency}

It was found that the vast majority ( $n=96,99 \%$ ) had no previous vein surgery, while only one (1\%) patient underwent the surgery. Only six (6.2\%) patients had previous endovenous laser therapy, and only nine (9.3\%) patients were found to have previous sclerotherapy. Furthermore, patients with reflux were compared to patients without reflux using the chi-square test. It was observed that patients with reflux had significantly higher rates of previous endovenous laser therapy $(\mathrm{P}=0.02)$. On the other hand, patients without reflux had significantly higher rates of sclerotherapy $(\mathrm{P}=0.006)$ (Table 2$)$.

\begin{tabular}{|l|l|l|l|l|}
\hline Previous treatment & Yes/ No & With Reflux (N=53) & Without Reflux (N=44) & P value \\
\hline Previous endovenous laser therapy & Yes & $6(11.32)$ & 0 & $0.021^{\star}$ \\
\hline Previous sclerotherapy & No & $47(88.67)$ & $44(100)$ & $8(18.18)$ \\
\hline
\end{tabular}

TABLE 2: Previous treatment of venous insufficiency among the study population

*Level of significance at $P$ value $\leq 0.05$

\section{Risk factors for saphenous vein insufficiency}

Out of the 97 included patients, we found that 21 (21.6\%) patients had diabetes mellitus, 11 (11.35\%) patients have hypertension, and 15 (15.5\%) patients have high lipid levels. All of the included patients ( $\mathrm{n}=$ $97,100 \%)$ were found to be non-smokers. Also, they did not have heart diseases ( $\mathrm{n}=97,100 \%)$. In regards to varicosities, 40 (41.2\%) patients were found to have a family history of varicosities. As for field work, 29 (29.9\%) patients were found to have field work. The majority ( $n=79,81.4 \%$ ) were found to be receiving oral contraceptive pills, and we also found that $46(52.2 \%)$ patients had less than or equal to three pregnancies. Also, the risk factors in both patients with reflux and those without reflux were compared. It was observed that hypertension was significantly higher $(\mathrm{p}=0.001)$ in patients without reflux. However, previous pregnancies and field work were higher in patients with reflux with a $\mathrm{P}$ value 0.018 and $<0.033$, respectively.

\section{Reflux status}

A total of 97 (100\%) female patients were included in this study from King Abdulaziz Medical City in Riyadh, Saudi Arabia out of which, 53 (54.6\%) patients were suffering from saphenous reflux while 44 (45.4\%) patients had no saphenous reflux.

\section{Determination of risk factors associated with saphenous vein insufficiency (with or without saphenous reflux)}

Our results showed that patients without reflux were older than patients with reflux; however, the difference was insignificant $(\mathrm{p}=0.565)$. In terms of BMI, patients with reflux and patients without reflux had a mean 
BMI of $30.7 \pm 11.7 \mathrm{~kg} / \mathrm{m} 2$ and $30.8 \pm 6.6 \mathrm{~kg} / \mathrm{m} 2$. The difference was also insignificant between the two groups $(\mathrm{p}=0.935)$. Regarding diabetes mellitus, we found that 12 (27.3\%) diabetes mellitus patients were without reflux while nine (17.0\%) diabetes mellitus patients were with reflux. The difference was also insignificant $(p=0.164)$. Similar findings were observed concerning high lipid levels; it was found that the proportion of patients without reflux who had high lipid levels $(n=10,22.7 \%)$ was insignificantly larger than that of patients with reflux who had high lipid levels $(n=5,9.4 \%),(p=0.064)$. A statistically significant difference $(\mathrm{p}=0.001)$ was found between hypertension patients without reflux and those with reflux. Interestingly, the proportion of hypertension patients without reflux $(n=10,22.7 \%)$ was larger than that of hypertension patients with reflux $(n=1,1.9 \%)$. In regard to field work, a statistically significant difference $(p=0.018)$ was observed between the two groups (with \& without reflux). We found that the proportion of field workers who had reflux $(n=21,39.6 \%)$ was larger than that of field workers who had no reflux $(n=8,18.2 \%)$. The same pattern was observed concerning previous pregnancies (more than three); we found that the proportion of patients with reflux who had more than three previous pregnancies $(n=30,56.6 \%)$ which was larger than that of patients without reflux who had more than three previous pregnancies $(n=12,27.3 \%)$. A statistically significant difference was observed between the two groups $(p=0.033)$. Conversely, there were no statistically significant differences between the two groups in terms of using oral contraception pills and family history of varicosities, ( $\mathrm{p}=0.366$ and $\mathrm{p}=0.395$ respectively) (Table 3).

\begin{tabular}{|c|c|c|c|}
\hline Risk factors & With reflux Mean \pm SD / Count (\%) & Without reflux Mean \pm SD / Count (\%) & P value \\
\hline Age (years) & $42.3 \pm 11.7$ & $43.8 \pm 13.9$ & 0.565 \\
\hline BMI (kg/m²) & $30.7 \pm 5.6$ & $30.8 \pm 6.6$ & 0.935 \\
\hline Diabetes mellitus & $9(1 / .0 \%)$ & $12(27.3 \%)$ & 0.164 \\
\hline Hypertension & $1(1.9 \%)$ & $10(22.7 \%)$ & $0.001^{\star}$ \\
\hline High lipid levels & $5(9.4 \%)$ & $10(22.7 \%)$ & 0.064 \\
\hline Field work & $21(39.6 \%)$ & $8(18.2 \%)$ & $0.018^{x}$ \\
\hline Oral contraceptive pills & $11(20.8 \%)$ & $7(15.9 \%)$ & 0.366 \\
\hline Family history of varicosities & $23(43.4 \%)$ & $17(38.6 \%)$ & 0.395 \\
\hline Previous pregnancies (More than 3 ) & $30(56.6 \%)$ & $12(27.3 \%)$ & $0.033^{*}$ \\
\hline Smoking & \multicolumn{3}{|c|}{ Not applicable, as all patients are non-smokers } \\
\hline Heart diseases & \multicolumn{3}{|c|}{ Not applicable, as all patients have no heart diseases } \\
\hline
\end{tabular}

\section{TABLE 3: Risk factors for venous insufficiency with and without saphenous reflux}

\section{Discussion}

Chronic venous disease (CVD) comprises a wide range of chronic conditions that are related to or caused by veins, such as telangiectases, varicose veins, CVI especially in the saphenous vein, phlebitis, skin hyperpigmentation, and ulcer formation [16].

$\mathrm{CVI}$ is considered to be among the most common manifestations of CVD. CVI accounts for a condition that affects the venous system of the lower limbs. CVI often refers to the more progressive forms of venous disorders, including skin hyperpigmentation, venous eczema, and ulcers. Nevertheless, because incompetent valves and increased venous pressure are also involved in varicose veins, the term CVI is used to represent the full spectrum of manifestations of CVD [6,17].

The clinical, aetiological, anatomical, and pathological (CEAP) classification system was created in order to standardize the reporting and treatment of the diverse manifestations of CVD. The revised version of the classification additionally contains definitions of clinical signs and suggests three levels of investigations adjusted to the clinical stage $[12,18]$. Both the basic CEAP and comprehensive CEAP were created to allow uniform diagnosis and comparison of different patient populations [18].

The GSV and the short saphenous vein (SSV), along with perforator veins (PV) are the most commonly affected veins by abnormal valve function [19]. The GSV, the longest vein in the human body, is a superficial 
vein that extends from the dorsum of the foot to the upper thigh and groin. The significance of GSV comes from its role in returning blood from the leg to the heart and is also used in several major medical procedures [20]. Since data about CVI, including CVD and saphenous vein insufficiency, in the female population in Saudi Arabia are still lacking, our current study aimed to get a better understanding about the underlying disease, and also to determine risk factors associated with saphenous vein insufficiency in female patients in Riyadh, Saudi Arabia.

Our results showed that $54.6 \%$ of the total population was suffering from saphenous reflux. Two studies with only female populations, that were conducted in 2005 and 2007, elaborated related information that GSV reflux was present in $60 \%$, and $39 \%$, respectively, of the total extremities examined. SSV reflux was found to be $3 \%$, and $2 \%$, respectively, while both GSV and SSV reflux were found to be present in $17 \%$, and $5 \%$, respectively, of the total extremities examined [21-22].

Over the years, numerous studies have investigated the prevalence of CVI, especially saphenous vein insufficiency, and the associated risk factors. The results vary according to the geographic location and the population being studied [7-9]. The Edinburgh Vein Study reported that the prevalence of all categories of varicose veins and CVI increased with age $(p<0.001)$, while no relation was found with social class [15]. The same study investigated the lifestyle risk factors in another paper. It reported that obesity, previous pregnancy, lower use of oral contraceptive pills, and mobility at work may be implicated in venous reflux in women, while in men, height, and straining at stool may be implicated as risk factors [23].

In the current study, we found that field work and previous pregnancies (more than three) are significantly associated with saphenous reflux ( $p=0.018 \& \mathrm{p}=0.033$, respectively). On the other hand, diabetes mellitus, high lipid levels, taking oral contraception pills, and family history of varicosities were found to have no association with saphenous reflux. Unexpectedly, the proportion of hypertension patients without reflux (22.7\%) was significantly larger than that of hypertension patients with reflux $(1.9 \%)(p=0.001)$. This may be due to the very small number of hypertensive patients with reflux (only one patient). In the current study, we found that field work and previous pregnancies (more than three) are significantly associated with saphenous reflux $(p=0.018 \& p=0.033$, respectively).

Turning to the treatment method, patients with reflux had significantly higher rates of endovenous layer therapy ( $\mathrm{p}=0.021)$. While the same patient group showed significantly lower rates of sclerotherapy compared to patients without reflux ( $\mathrm{p}=0.006$ ). Results from Edinburgh Vein Study showed that the prevalence of all categories of varicose veins and CVI increased with age $(p<0.001)$, while no relation was found with social class [15]. It was also reported that obesity, previous pregnancy, lower use of oral contraceptive pills, mobility at work may be implicated in venous reflux in women [23]. In alignment with the Edinburgh Vein Study, constipation was also found to be one of the lifestyle risk factors associated with CVI [23-24]. Another study showed that obesity, lack of physical activity, and the number of previous pregnancies were significantly associated with CVI in women [25-26].

We recommend conducting further prospective studies preferably with a larger sample size to get a more accurate estimation of the prevalence of saphenous venous insufficiency and better determine the potential risk factors in our specific population, especially adult females with high risk.

\section{Conclusions}

We conclude that leg pain and leg swelling were found to be the most common symptoms of saphenous vein insufficiency. In addition, field work and high frequency of previous pregnancies may be associated with a higher risk of developing saphenous vein insufficiency with reflux ( $p=0.018$ and $p=0.033$, respectively). Therefore, it is very important to raise the awareness of healthcare providers and female patients about this disease, its symptoms, and the preventable risk factors in order to minimize its prevalence and ensure a better quality of life for Saudi females.

\section{Additional Information \\ Disclosures}

Human subjects: All authors have confirmed that this study did not involve human participants or tissue. Animal subjects: All authors have confirmed that this study did not involve animal subjects or tissue. Conflicts of interest: In compliance with the ICMJE uniform disclosure form, all authors declare the following: Payment/services info: All authors have declared that no financial support was received from any organization for the submitted work. Financial relationships: All authors have declared that they have no financial relationships at present or within the previous three years with any organizations that might have an interest in the submitted work. Other relationships: All authors have declared that there are no other relationships or activities that could appear to have influenced the submitted work.

\section{References}

1. Gale SS, Lee JN, Walsh ME, Wojnarowski DL, Comerota AJ: A randomized, controlled trial of endovenous 
thermal ablation using the 810-nm wavelength laser and the ClosurePLUS radiofrequency ablation methods for superficial venous insufficiency of the great saphenous vein. J Vasc Surg. 2010, 52:645-50. doi: 10.1016/j.jvs.2010.04.030

2. Boersma D, van Eekeren RR, Werson DA, van der Waal RI, Reijnen MM, de Vries JP: Mechanochemical endovenous ablation of small saphenous vein insufficiency using the ClariVein ${ }^{\circledR}$ device: one-year results of a prospective series. Eur J Vasc Endovasc Surg. 2013, 45:299-303.

3. Boersma D, Kornmann VN, van Eekeren RR, Tromp E, Ünlü Ç, Reijnen MM, de Vries JP: Treatment modalities for small saphenous vein insufficiency: systematic review and meta-analysis. J Endovasc Ther. 2016, 23:199-211.

4. van Eekeren RR, Boersma D, Holewijn S, Werson DA, de Vries JP, Reijnen MM: Mechanochemical endovenous ablation for the treatment of great saphenous vein insufficiency. J Vasc Surg Venous Lymphat Disord. 2014, 2`:282-8. 10.1016/j.jvsv.2014.01.001

5. Memetoglu ME, Kurtcan S, Kalkan A, Özel D: Combination technique of tumescent anesthesia during endovenous laser therapy of saphenous vein insufficiency. Interact Cardiovasc Thorac Surg. 2010, 11:774-8.

6. Rasmussen LH, Lawaetz M, Bjoern L, Vennits B, Blemings A, Eklof B: Randomized clinical trial comparing endovenous laser ablation, radiofrequency ablation, foam sclerotherapy and surgical stripping for great saphenous varicose veins. Br J Surg. 2011, 98:1079-1087.

7. Rass K, Frings N, Glowacki P, Hamsch C, Vogt T, Tilgen W: Comparable effectiveness of endovenous laser ablation and high ligation with stripping of the great saphenous vein: two-year results of a randomized clinical trial (RELACS study). Arch Dermatol. 2012, 148:49-58.

8. Doganci S, Demirkilic UF: Comparison of $980 \mathrm{~nm}$ laser and bare-tip fibre with $1470 \mathrm{~nm}$ laser and radial fibre in the treatment of great saphenous vein varicosities: a prospective randomised clinical trial. Eur J Vasc Endovasc Surg. 2010, 40:254-9. 10.1016/j.ejvs.2010.04.006

9. Helmy ElKaffas K, ElKashef O, ElBaz W: Great saphenous vein radiofrequency ablation versus standard stripping in the management of primary varicose veins-a randomized clinical trial. Angiology. 2011, 62:4954. 10.1177/0003319710380680

10. Shadid N, Ceulen R, Nelemans P, et al.: Randomized clinical trial of ultrasound-guided foam sclerotherapy versus surgery for the incompetent great saphenous vein. Br J Surg. 2012, 99:1062-70. 10.1002/bjs.8781

11. Biemans AA, Kockaert M, Akkersdijk GP, et al.: Comparing endovenous laser ablation, foam sclerotherapy, and conventional surgery for great saphenous varicose veins. J Vasc Surg. 2013, 58:727-34. 10.1016/j.jvs.2012.12.074

12. Pronk P, Gauw SA, Mooij MC, Gaastra MT, Lawson JA, Van Goethem AR, Van Vlijmen-van Keulen CJ: Randomised controlled trial comparing sapheno-femoral ligation and stripping of the great saphenous vein with endovenous laser ablation $(980 \mathrm{~nm})$ using local tumescent anaesthesia: one year results. Eur J Vasc Endovasc Surg. 2010, 40:649-56.

13. García-Gimeno M, Rodríguez-Camarero S, Tagarro-Villalba S, et al.: Reflux patterns and risk factors of primary varicose veins' clinical severity. Phlebology. 2013, 28:153-161. 10.1258/phleb.2011.011114

14. Selçuk Kapısız N, Uzun Kulaoğlu T, Fen T, Kapısız H: Patterns of saphenous venous reflux in women presenting with lower extremity telangiectasi as potential risk factors for varicose veins with superficial venous reflux. Int J Vasc Med. 2014, 2014:1-6.

15. Robertson L, Evans C, Lee A, Allan P, Ruckley C, Fowkes F: Incidence and risk factors for venous reflux in the general population: Edinburgh vein study. Eur J Vasc Endovasc Surg. 2014, 48:208-214. 10.1016/j.ejvs.2014.05.017

16. Memetoğlu ME, Kurtcan S, Erbasan O, Özel D: Endovenous ablation with a $940 \mathrm{~nm}$ laser for the treatment of great saphenous vein insufficiency: short-to mid-term results. Diagn Interv Radiol. 2012, 18:106-10.

17. Cronenwett JL, Johnston KW, Raffetto J, Eberhardt RT: Chronic venous disorders: general considerations . Rutherford's Vascular Surgery, 7th Edition. Cronenwett JL, Johnston KW (ed): Saunders-Elsevier, Philadelphia; 2010. 831:843.

18. Dermody M, Schul MW, O’Donnell TF: Thromboembolic complications of endovenous thermal ablation and foam sclerotherapy in the treatment of great saphenous vein insufficiency. Phlebology. 2015, 30:357-64.

19. Baliyan V, Tajmir S, Hedgire S, Ganguli S, Prabhakar A: Lower extremity venous reflux. Cardiovasc Diagn Ther. 2016, 6:533-543.

20. Padavinangadi A, Kumar N, Swamy R, Satheesha N, Mohandas Rao K: Unilateral double great saphenous vein: a clinically significant case report. J Cardiovasc Echogr. 2015, 25:116-118. 10.4103/2211-4122.172491

21. Engelhorn C, Engelhorn A, Cassou M, Salles-Cunha S: Patterns of saphenous reflux in women with primary varicose veins. J Vasc Surg. 2005, 41:645-651.

22. Engelhorn C, Engelhorn ALV, Cassou MF, Salles-Cunha S: Patterns of saphenous venous reflux in women presenting with lower extremity telangiectasias. Dermatol Surg. 2007, 33:282-288. 10.1111/j.15244725.2007.33063.x

23. Fowkes F, Lee A, Evans C, Allan P, Bradbury A, Ruckley C: Lifestyle risk factors for lower limb venous reflux in the general population: Edinburgh Vein Study. Int J Epidemiol. 2001, 30:846-852.

24. Zoller B, Ji J, Sundquist J, Sundquist K: Family history and risk of hospital treatment for varicose veins in Sweden. Br J Surg. 2012, 99:948-953. 10.1002/bjs.8779

25. Jawien A: The influence of environmental factors in chronic venous insufficiency . Angiology. 2003, 54:S19S31.

26. Beebe-Dimmer JL, Pfeifer JR, Engle JS, Schottenfeld D: The epidemiology of chronic venous insufficiency and varicose veins. Ann Epidemiol. 2005, 15:175-184. 